\title{
Localized inter-organizational linkages, agglomeration effects, and the innovative performance of firms
}

\section{J. Knoben}

Received: 23 February 2007 / Accepted: 16 March 2008 / Published online: 10 April 2008

(C) The Author(s) 2008

\begin{abstract}
This paper focuses on the questions to what extent agglomeration effects and localized inter-organizational linkages influence different types of innovative performance of firms. Doing so adds to the relatively scarce firm-level literature regarding the role of regional environment for the innovative performance of firms by disentangling the often conflated effects of agglomeration effects and localized interorganizational linkages. Based on data from the Dutch automation services, we show that agglomeration economies and localized inter-organizational linkages have different effects on different types of innovative performance of firms.
\end{abstract}

JEL Classification $\mathrm{R} 10 \cdot \mathrm{R} 12 \cdot \mathrm{O} 18 \cdot \mathrm{O} 31$

\section{Introduction}

There is a large body of the literature that argues that the characteristics of a firm's regional environment may help explain why some firms are more innovative than others (for overviews see, Feldman 1999; Moulaert and Sekia 2003). Many different concepts, such as clusters, innovative milieus, regional systems of innovation, learning regions, and industrial districts, have been introduced and studied to substantiate this claim (Moulaert and Sekia 2003). Despite their mutual differences, these concepts have in common that they all emphasize the importance of combinations of agglomeration

\footnotetext{
J. Knoben

The Netherlands Institute for Spatial Research, The Hague, The Netherlands

J. Knoben $(\varangle)$

Tilburg University, Room p.3.110, Warandelaan 2,

P. O. Box 90153, 5000 LE, Tilburg, The Netherlands

e-mail: j.knoben@uvt.nl
} 
effects and localized inter-organizational linkages for the innovativeness of firms. Thereby, these concepts incorporate two theoretical mechanisms based on geographical proximity that explain the innovativeness of firms (Gordon and Mccann 2000).

Empirical evidence for the regional concentration of innovative activities is widespread and has developed into a line of reasoning that the regional environment is crucial for a firm's innovative performance (Beugelsdijk 2007). However, the majority of this empirical evidence is not built upon micro-level studies but is largely deduced from the macro-level phenomenon of regional clustering of innovative activities (Beugelsdijk 2007; Lever 1972; Phelps 1992). As a result of taking the region, rather than the firm, as the level of analysis, actual localized inter-organizational linkages are often not observed. Instead, it is assumed that when firms co-locate in large numbers, localized inter-organizational linkages are present (Beugelsdijk 2007; Dicken and Malmberg 2001). However, previous empirical research has shown that this assumption does not necessarily hold and that agglomerations and localized inter-organizational linkages are, at the firm-level, only weakly related (Arndt and Sternberg 2000; Mota and De Castro 2004; Sohn 2004). As a result, the possibility that firms with localized inter-organizational linkages that are not located in dense concentrations of firms might be just as innovative as their spatially concentrated counterparts, or that agglomeration effects without any localized inter-organizational linkage account for the enhanced innovativeness of firms cannot be excluded (Appold 1995). In other words, research has entangled the effects resulting from agglomerations and localized inter-organizational linkages (Knoben and Oerlemans 2006), and is therefore unable to attribute the enhanced innovativeness of firms in spatial concentrations to either of these roles of geographical proximity.

As a response to this critique, several firm-level studies have been conducted over the last decades, even though such studies remain relatively scarce (Beugelsdijk 2007). Among the noteworthy exceptions are Baptista and Swann (1998), Sternberg and Arndt (2001), Fritsch (2004), Fritsch and Franke (2004), Mariani (2004), and Hendry and Brown (2006). ${ }^{1}$ However, the majority of these studies does not include separate measures of agglomeration effects and localized inter-organizational linkages and are therefore unable to disentangle both effects of geographical proximity. An exception is the research by Fritsch (2004), and Sternberg and Arndt (2001) who do disentangle both roles of spatial proximity and find that especially combinations of local and non-local inter-organizational linkages, rather than agglomeration effects, are conducive to the innovative performance of firms. Despite this valuable exception, there still is a need for more firm-level insights with regard to the specific role of combinations of agglomeration effects and localized inter-organizational linkages for the innovative performance of firms (Beugelsdijk 2007; Boschma and Weterings 2005; Mariani 2004).

The research presented in this paper focuses on the question to what extent agglomeration effects and localized inter-organizational linkages influence the innovative performance of firms. To answer this question, firm-level data gathered in the Dutch automation service sector are utilized. By answering this question, this research adds

\footnotetext{
1 Furthermore, there are several firm-level studies that have focused on different types of firm performance, such as market size (Appold 1995), firm value (Boasson et al. 2005), technology adoption (Harrison et al. 1996), export performance (Malmberg et al. 2000), and productivity (Wheeler 2006).
} 
to the relatively scarce firm-level literature by disentangling two theoretical mechanisms that have, so far, often been entangled. Thereby, more detailed insights will be generated with regard to how geographical proximity influences the innovativeness of firms. Moreover, in many European countries, large parts of regional economic policy are aimed at stimulating firm innovativeness by facilitating firm co-location, local inter-organizational contacts, or both (Gustavsen et al. 2007). In this regard, this research will provide firm level insights into whether such policy is likely to have an impact on firm innovativeness at all. If so, it will also yield insights into which kind of innovativeness is most likely to be stimulated by different forms of regional policy (i.e. stimulating co-location of firms, stimulating inter-organizational collaboration, or combinations thereof).

This paper will start with a brief discussion on the impact of agglomerations and localized inter-organizational linkages on firm innovativeness (Sect. 2). Subsequently, the operationalization of the concepts used in this theoretical discussion will be presented together with information with regard to the data collection procedure (Sect. 3). In Sect. 4, the data-analysis and the obtained results will be discussed. Finally, the implications of these findings will be presented (Sect. 5).

\section{Geographical proximity and firm innovativeness}

As has been argued in the above, two mechanisms through which geographical proximity between firms influences firm innovativeness can be identified in the literature (Gordon and Mccann 2000; Moulaert and Sekia 2003). The first mechanism, agglomeration effects is based on geographical proximity between groups of firms without the necessity of any localized inter-organizational interaction (Gordon and Mccann 2000). The second mechanism refers to geographical proximity between two or more interacting organizations and requires the active exchange of resources (e.g. knowledge) or even collaborative innovative activities (Knoben and Oerlemans 2006). In short, the first mechanism refers to being in a spatial concentration of economic activities, whereas the second mechanism refers to interacting with other local organizations. Both mechanisms through which geographical proximity can influence firm innovativeness will be discussed here. The aim of discussing these mechanisms separately is not to show that both are not related and will not simultaneously (in the same region). Rather, the objective is to show that there are two mechanisms which might operate simultaneously and that, in order to correctly assess how geographical proximity influences firm innovativeness, both need to be (empirically) disentangled.

\subsection{Agglomeration effects}

Agglomeration effects are basically spatial economies of scale. These economies of scale exist only over limited spatial distances because of transaction costs of overcoming geographical distance, such as transport and communication costs (Baranes and Tropeano 2003). Therefore, there is a spatial limit over which firms can benefit from these particular economies of scale which induces firms and labor to concentrate in certain regions (Gordon and Mccann 2000). In short, spatial concentration of 
economic activities leads to advantages for firms that can only be obtained by being part of that spatial concentration.

Even though agglomeration economies can be grouped in different ways, the contemporary literature usually distinguishes between localization economies (MarshallArrow-Romer externalities) and urbanization economies (Jacobs-externalities) (Feldman 1999). Whereas localization economies are benefits of intra-industry concentration, urbanization economies are benefits of inter-industry concentration. Localization economies refer to the effects that are produced by having many firms from the same industry in a single area, such as a common pool of highly skilled labor, whereas urbanization economies refer to the effects of having firms from different industries in the area, such as reductions in transport costs.

Besides these tangible spatial externalities, more intangible benefits may arise from the spatial concentration of firms as well. These are caused by the fact that knowledge is partially non-rival and not completely appropriable (Breschi and Lissoni 2001). As a result, unintended knowledge diffusions between firms within a region are larger than those among geographically dispersed establishments (Jaffe et al. 1993). Knowledge diffusion can happen in numerous ways, which include patent citations, the mobility of skilled labor, and reverse engineering of traded goods (Feldman 1999). Through these processes, (tacit) knowledge can become implanted in geographical regions enabling firms within those regions to draw from this knowledge (Appold 1995). This way, firms can get access to the knowledge that is available in their geographical environment for free, which can enhance their innovativeness (Oerlemans et al. 2001). Such knowledge spillovers are generally found to be driven by high levels of R\&D and knowledge creation within a region.

Besides the positive effects of agglomeration economies described in the above, the literature also emphasizes several downsides of being located in an agglomeration, mostly related to competition effects. When establishments agglomerate in space, there will be competition for land, which drives up land costs and creates a centrifugal force in the region (Flyer and Shaver 2003). Furthermore, establishments will have to compete for qualified labor and other inputs. On the output side, spatial competition is likely to be an important force as well. If a market in a certain region is saturated, it will be more difficult for new establishments to get a foothold in that region (Sohn 2004). Moreover, there might be a negative self-selection effect of firms in agglomerations. Alcacer (2006) concludes in an empirical study that more capable firms are more likely to stop rivals from entering their market area and can more effectively force weaker firms out. As a result, the stronger firms end up being located in relative isolation, whereas the weaker firms end up in agglomerations since they lack to strength to drive competitors out of their market area and to deter new entrants from locating near them.

\subsection{Localized inter-organizational linkages}

The main difference between the effects of localized inter-organizational linkages and the effects of agglomerations described in the above is that whereas agglomeration effects do not require actual interaction between firms but largely accrue in an atomistic way (Gordon and Mccann 2000), localized inter-organizational linkages refer to actual interaction with other firms and organizations. 
In this paper, two types of localized inter-organizational linkages are distinguished, namely, localized external linkages and localized inter-organizational relations (IORs). The main difference is that external linkages refer to all interactions between a firm and other organizations with knowledge acquisition for its innovative activities as its primary goal. These interactions need not be repetitive and two-way traffic is not necessary. In contrast, inter-organizational relations are long-term collaborations between actors in which activities are jointly carried out. In these relations two-way traffic and mutual adjustment, and intensive communication is a given. Examples include the co-development of products, joint R\&D, joint-ventures, and so on.

Both types of linkages are important for firm innovativeness since they allow firms to get access to resources that would not be available (or only at higher costs) through the market. The importance of inter-organizational linkages for firm performance has been substantiated empirically for different measures of firm performance, for example, firm survival (Mitchell and Singh 1996), profit rates (Hagedoorn and Schakenraad 1994), innovation rates (Pittaway et al. 2004), and firm growth (Stuart 2000). In general, firms that have more inter-organizational linkages can access the necessary resources more easily and therefore experience an increased performance (Ahuja 2000; Love and Roper 2001).

The linkages described in the above are in essence a-spatial. The importance of geographical proximity in inter-organizational linkages lies in the fact that localization facilitates face-to-face interactions (both planned and serendipitous) which is argued to foster the exchange of tacit knowledge and resources (Kogut and Zander 1992; Torre and Rallet 2005). Tacit knowledge, in turn, is often argued to be one of the main drivers of the innovativeness of firms because only tacit knowledge, as opposed to codified knowledge, is argued to contain truly new insights (Howells 2002). The larger the distance between actors, the more difficult it is to transfer tacit forms of knowledge and, therefore, the more difficult it is to transfer resources that are conducive to the innovativeness of a firm. Based on this line of reasoning, firms with more localized inter-organizational linkages would experience higher levels of innovative performance.

Similar to agglomeration economies, however, there are also downsides to maintaining localized inter-organizational linkages. For example, some authors argue that there is no reason to assume that nearby firms will be the most suitable partners (Rosenkopf and Almeida 2003), and that well-run firms actually benefit from being freed from nearby partners (Appold 1995). Moreover, by focusing on localized linkages, firms can become (geographically) locked-in resulting in unresponsiveness to developments outside their region (Alberti 2006; Boschma 2005; Narula 2002). In this perspective, it seems plausible that firms with combinations of local and non-local inter-organizational linkages experience the highest levels of innovative performance (Arndt and Sternberg 2000; Sternberg and Arndt 2001).

\subsection{The entanglement of two theoretical mechanisms}

Based on the above, it could be argued that the innovativeness of firms can both benefit from and be hampered by agglomeration effects as well as by localized interorganizational linkages. However, since both mechanisms are based on geographical 
proximity between firms, they are likely to operate simultaneously and are nearly impossible to disentangle when observed at the level of the region. As a result, empirical studies with regard to the impact of geographical proximity on the innovativeness of firms at the level of the region have often compressed both mechanisms into a single argument and measurement. Therefore, the effects of spatial concentrations of firms on the innovativeness of these firms cannot be convincingly attributed to either one of both mechanisms, nor can it be excluded that one of these mechanisms fully accounts for the found effects. Finally, it could even be the case that one of the mechanisms negatively impacts on the innovativeness of firms for reasons discussed in the above. In order to assess whether firms benefit or suffer from agglomeration effects and/or localized inter-organizational linkages data at the level of the establishment will have to be analyzed. An important factor for successfully performing such an analysis is to minimize the level of firm-specific heterogeneity (Beugelsdijk 2007), in the next section(s) this issue will specifically be addressed.

\section{Empirical application}

In order to explore the effects of both agglomeration economies and localized interorganizational linkages on the innovativeness of firms, reliable indicators of all three concepts have to be used. The operationalization of these concepts will be discussed subsequently.

\subsection{Firm innovativeness}

Commonly used indicators of a firm's innovativeness are R\&D expenditures and patents. Both indicators have several deficiencies however. A drawback of using R\&D expenditures is that they reflect an input of the innovative process, rather than an output. Some firms might be able to use their R\&D budget more efficiently and reach the same level of innovative output with fewer inputs. Moreover, as a measure of innovativeness, R\&D surveys tend to undercount R\&D in small firms and service firms (Kleinknecht 1991). Both arguments make the use of R\&D expenditures as an indicator of innovativeness problematic.

With regard to the use of patents as an indicator of innovative firm performance, it should be noted that many innovations are not patented, while the willingness to patent varies across sectors and firm size classes. Again, small firms and service firms are less likely to patent as compared to other firms (Arundel and Kabla 1998; Kleinknecht 1996), which poses difficulties when using this indicator.

A more valid measurement of innovativeness in the context of this research is the presence of innovative sales. A clear advantage of this measurement of innovative outcomes is that it captures the confrontation of the (product) innovation with the demands of the market and thus is more close to the general accepted definition of innovation that includes the market introduction of the innovation (Hagedoorn and Cloodt 2003).

A second dimension of innovativeness taken into account in this paper is the level of newness of the innovation. This distinction is important since research has shown 
that different types of innovativeness are influenced by different types of resources (e.g. Oerlemans et al. 1998). In this paper newness of innovation is defined by three categories, namely, products that are improved versions of products that were already produced by the firm, products that are new to the firm, and products that are new to the firm's market as a whole.

In order to accommodate the demands posed to a reliable measurement of innovativeness for small firms and service firms, the self-reported innovation measures developed for the community innovation survey (CIS) have been used. Firms are asked whether they introduced new or improved products, services or processes during the two previous years for each of the categories of newness presented in the above. Research has shown that these subjective indicators are just as valid as measures of innovative performance as the more objective indicators mentioned in the above (Hagedoorn and Cloodt 2003).

\subsection{Agglomeration economies}

In order to disentangle the effects of economies of localization, urbanization, and knowledge spillovers, data on all three concepts has been obtained. Economies of urbanization are measured as the number of inhabitants per square kilometer in a region, whereas economies of localization are measured as the percentage of firms in a region that is active in the same economic sector. These data are obtained from the Dutch Central Bureau of Statistics (CBS).

The R\&D intensity of the region and the average level of education in the region have been used as indicators for the amount of available knowledge spillovers within a region. Regarding the former indicator, the CBS only publishes data on the level of the province; therefore, an alternative database has been used (data adopted from Figs. 4.18 and 4.19 from Van Oort 2002). This database contains information with regard to the average amount of $\mathrm{R} \& \mathrm{D}$ expenditures per employee in a region. Regarding the latter indicator, CBS data regarding the share of the population in a region with a university or polytechnic degree has been used.

For all these indicators of agglomeration economies, however, it seems possible that its benefits exceed to borders of the administrative region. As a result, spatial autocorrelation might lead to misspecifications of the models. Checks for spatial autocorrelation with SpaceStat revealed that for all regional variables, except for the regional average level of education, spatial autocorrelation occurred (based on Moran's I). To correct for this problem, spatially weighted versions of the regional variables that were spatially autocorrelated have been constructed. For each of these variables the value for the region in which a firm is located as well as the average of the value of the neighboring regions (the spatial lag) have been included in the analyses. ${ }^{2}$

All regional variables mentioned in the above are constructed at the level of the NUTS-3-region as defined by the European Statistical Office (Eurostat). The Netherlands consists of 40 such regions. This geographical scope has been chosen because earlier research has shown that the NUTS-3-region is the most appropriate unit of

\footnotetext{
2 Other ways of spatial weighing have been used as well. The results of the analyses did not change, however, leading to the choice for the simplest version of spatial weighing.
} 
analysis to measure spatial externalities in the Netherlands (Van Stel and Nieuwenhuijsen 2004).

It should be noted that many more regional characteristics can be taken into account, such as regional GDP, presence of a (technical) university, accessibility, and so on. However, these regional indicators correlate problematically high with the indicators already used, which would lead to severe multicollinearity issues. Therefore, the analysis has been restricted to the four regional characteristics discussed in the above. ${ }^{3}$

\subsection{Localized inter-organizational linkages}

As discussed earlier, two different types of inter-organizational linkages have been incorporated in this research, namely, linkages that constitute active knowledge intensive collaboration between organizations, named inter-organizational relationships (IORs), and more general linkages that firms utilize to gather the knowledge for their innovative activities, named external linkages.

With regard to the former type of inter-organizational linkage, data regarding the total number of IORs of a firm and whether the main IOR of the firm was located within $20 \mathrm{~km}$ have been gathered. Only specific information with regard to the main IOR of a firm has been gathered since a firm-level survey has insufficient space to question all IORs of a firm in detail. Moreover, the problem of non-response becomes exceedingly large when firms are asked about characteristics of more than one IOR. The approach of focusing on the main IOR of a firm has been adopted from the community innovation survey (CIS). Even though the total number of IORs of a firm is not an indicator of localized inter-organizational linkages, it is included to ensure that the variable that captures the localization of a firm's main IOR does not just capture the existence of IORs in general.

Regarding the latter type of inter-organizational linkage, data regarding the percentage of external linkages used by a firm in its innovative processes that is located within $20 \mathrm{~km}$ of the responding firm has been gathered. Given the indication in the literature that combinations of local and non-local external linkages yield the best innovative performance, a squared term of the latter indicator is included in the analyses as well. These data were obtained by asking firms to indicate the total amount of external linkages they had (distinguishing between buyers, suppliers, competitors, consultants, research institutes, universities, innovation centers, and sectoral institutes), as well as the amount of these sources that was located within a radius of $20 \mathrm{~km}$ from their establishment. From this information, the percentage of their external linkages that is localized could be calculated.

\footnotetext{
3 To ensure that the analyses did not suffer from omitted region-specific effects, the sample has been split into two sub-samples in two different ways. The first division separated the provinces of North-Brabant and South-Holland ( 89 observations) from the rest of the provinces (114 observations). This division was made because these two provinces contain the majority of the industrial activities in the Netherlands. The second division separated the provinces of North-Holland, South-Holland, and Utrecht (96 observations) from the rest of the provinces (107 observations). This division was made because these provinces make up the Randstad-area, which is the economic core of the Netherlands. All of the analyses discussed in Sect. 4 have also been conducted for each of these four sub-samples. The results were highly similar for each of the sub-samples, indicating that bias resulting from omitted region-specific effects is unlikely to be present.
} 


\subsection{Firm characteristics}

As has been noted earlier, in order to validly analyze the role of agglomeration effects and localized inter-organizational linkages for the innovative performance of firms, firm-specific heterogeneity needs to be controlled for. Two ways to do so have been implemented in this research. First, a single sector design has been employed, which will be discussed in more detail in the next subsection. Second, several firm level characteristics have been included as control variables.

Regarding the latter, the size and age of a firm are included in the analyses. Many scholars argue that older and larger firms have an advantage in innovation due to stronger cash flows, higher assets as collateral for loan, wider access to knowledge and human capital skills. However, others state that smaller and younger firms have an advantage due to the ability to faster recognize opportunities, flexibility, less rigid management structures, and more appropriate incentive structures (Acs and Audretsch 1988; Audretsch and Acs 1991; Hansen 1992). In both cases, however, firm size and age should be controlled for. In a similar vein, a dummy variable that indicates if a firm is part of a larger organizational entity has been included because it is often argued that such firms have access to more resources, which effects their innovative performance (Tsai 2001).

Moreover, to correct for firm level differences the strength of a firm's internal knowledge base is taken into account (Oerlemans and Meeus 2005; Sternberg and Arndt 2001). The strength of the internal knowledge base of a firm is measured by the percentage of total turnover that is used for R\&D activities and, because small firms are less likely to have any formal $R \& D$, the percentage of highly educated personnel (polytechnic or university degree) in the firm.

An overview of all variables used in this research, their definitions, and some descriptive statistics can be found in Table 1. How the data underlying these descriptive statistics has been collected will be discussed in the next section.

\subsection{Data collection and non-response analysis}

In order to collect information with regard to the concepts discussed in the above, a questionnaire was mailed to all firms in the automation services sector in the Netherlands with more than five full-time employees. A single-sector design was chosen since there are large sectoral differences in terms of spatial distribution, the propensity to form (localized) inter-organizational linkages, and appropriate measures of innovative performance (Gatignon et al. 2002). Therefore, employing a multi-sectoral design would introduce large levels of heterogeneity that would subsequently need to be controlled for. Even though a single sector design poses severe limits on the generalizability of the obtained results, it is both more feasible and fruitful in this particular case.

The automation services sector was chosen because it is characterized by high levels of innovativeness, both in terms of inputs and outputs. Almost $3 \%$ of total value added is spent on innovative activities, as opposed to $1 \%$ (on average) for the other service sectors. Moreover, of all firms, $52 \%$ report to have successfully innovated over 
Table 1 Variable definitions and descriptive statistics

\begin{tabular}{|c|c|c|c|c|c|}
\hline Variable & Definition & Mean & Min & $\operatorname{Max}$ & Stdev \\
\hline $\begin{array}{l}\text { Introduction of improved } \\
\text { products }\end{array}$ & $\begin{array}{l}\text { Dummy indicating whether (1) } \\
\text { or not }(0) \text { the firm has intro- } \\
\text { duced improved versions of its } \\
\text { own products }\end{array}$ & 0.67 & 0 & 1 & 0.47 \\
\hline $\begin{array}{l}\text { Introduction or products } \\
\text { new to the firm }\end{array}$ & $\begin{array}{l}\text { Dummy indicating whether (1) } \\
\text { or not }(0) \text { the firm has introdu- } \\
\text { ced products that were new to } \\
\text { the firm }\end{array}$ & 0.70 & 0 & 1 & 0.46 \\
\hline $\begin{array}{l}\text { Introduction or products } \\
\text { new to the market }\end{array}$ & $\begin{array}{l}\text { Dummy indicating whether (1) } \\
\text { or not }(0) \text { the firm has introdu- } \\
\text { ced products that were new to } \\
\text { the market }\end{array}$ & 0.53 & 0 & 1 & 0.50 \\
\hline Localization effects & $\begin{array}{l}\text { Percentage of firms active in } \\
\text { commercial services in a } \\
\text { region }\end{array}$ & 0.56 & 0.45 & 0.67 & 0.06 \\
\hline $\begin{array}{l}\text { Spatial lag of localization } \\
\text { effects }\end{array}$ & $\begin{array}{l}\text { Spatially weighed average of } \\
\text { percentage of firms active in } \\
\text { commercial services in neigh- } \\
\text { boring regions }\end{array}$ & 0.55 & 0.47 & 0.63 & 0.04 \\
\hline Urbanization effects & $\begin{array}{l}\text { Number of inhabitants }(\times 1,000) \\
\text { per square kilometer in a } \\
\text { region }\end{array}$ & 0.86 & 0.17 & 3.09 & 0.66 \\
\hline $\begin{array}{l}\text { Spatial lag of urbanization } \\
\text { effects }\end{array}$ & $\begin{array}{l}\text { Spatially weighed average of } \\
\text { number of inhabitants } \\
(\times 1,000) \text { per square kilometer } \\
\text { in neighboring regions }\end{array}$ & 0.78 & 0.19 & 2.12 & 0.45 \\
\hline $\mathrm{R} \& \mathrm{D}$ Intensity of region & $\begin{array}{l}\text { R\&D expenditures }(\times 1,000 \\
\text { Euro }) \text { per full time employee } \\
\text { in a region }\end{array}$ & 0.72 & 0.24 & 1.96 & 0.41 \\
\hline $\begin{array}{l}\text { Spatial lag of } R \& D \\
\text { intensity of region }\end{array}$ & $\begin{array}{l}\text { Spatially weighed average of } \\
\text { R\&D expenditures }(\times 1,000 \\
\text { Euro) per full time employee } \\
\text { in neighboring regions }\end{array}$ & 0.67 & 0.33 & 1.39 & 0.19 \\
\hline Regional level of education & $\begin{array}{l}\text { Percentage of population in a } \\
\text { region with a university or } \\
\text { polytechnical degree }\end{array}$ & 25.67 & 17.20 & 35.13 & 5.78 \\
\hline Main IOR localized & $\begin{array}{l}\text { Dummy indicating whether (1) } \\
\text { or not }(0) \text { the main partner of a } \\
\text { firm is located within } 50 \mathrm{~km}\end{array}$ & 0.35 & 0 & 1 & 0.48 \\
\hline $\begin{array}{l}\text { Localized external } \\
\text { linkages (\%) }\end{array}$ & $\begin{array}{l}\text { Percentage of external linkages } \\
\text { of a firm with actors within } \\
20 \mathrm{~km}\end{array}$ & 19.12 & 0 & 100 & 26.46 \\
\hline $\begin{array}{l}\text { Localized external } \\
\text { linkages (squared) (\%) }\end{array}$ & $\begin{array}{l}\text { Squared percentage of external } \\
\text { linkages of a firm with actors } \\
\text { within } 20 \mathrm{~km}\end{array}$ & 1062.22 & 0 & 10000 & 2205.92 \\
\hline Size $(\ln )$ & $\begin{array}{l}\text { Natural logarithm of the number } \\
\text { of full time employees of the } \\
\text { firm }\end{array}$ & 2.55 & 0.41 & 5.62 & 1.00 \\
\hline Age & Age of the firm in years & 11.10 & 1 & 41 & 6.89 \\
\hline Part of larger organization & $\begin{array}{l}\text { Dummy indicating whether (1) } \\
\text { or not }(0) \text { a firm is part of a } \\
\text { larger organizational entity }\end{array}$ & 0.21 & 0 & 1 & 0.48 \\
\hline
\end{tabular}


Table 1 continued

\begin{tabular}{|c|c|c|c|c|c|}
\hline Variable & Definition & Mean & Min & Max & Stdev \\
\hline R\&D Intensity of firm & $\begin{array}{l}\text { Percentage of turnover of the } \\
\text { firm spend on } R \& D\end{array}$ & 14.96 & 0 & 100 & 19.36 \\
\hline Share of highly educated personnel & $\begin{array}{l}\text { Percentage of employees with } \\
\text { a university or polytechnical } \\
\text { degree }\end{array}$ & 63.72 & 0 & 100 & 31.56 \\
\hline Number of IORs & $\begin{array}{l}\text { Number of knowledge inten- } \\
\text { sive inter-organizational rela- } \\
\text { tions that a firm has }\end{array}$ & 1.24 & 0 & 10 & 1.70 \\
\hline
\end{tabular}

the past 2 years, as opposed to $23 \%$ (on average) for the other service sectors. The magnitude of inter-organizational relations is comparable to that in other service sectors (32\% for the automation services vs. $34 \%$ on average). Firms in the automation services focus almost exclusively on the domestic market, which ensures that the focus of the questionnaire on Dutch firms only does not bias the results.

Within the automation services sector, several different types of economic activities are carried out. The dominant activities are hardware consultancy, production and implementation of software and websites, automation of production processes, repair and maintenance of computers and other office appliances, network maintenance, and electronic security. The branch comprises about 17,500 firms $(2.5 \%$ of all firms in the Netherlands) and it employs about 123,800 persons (1.5\% of total employment). Taking 2001 as the base year, the number of jobs declined with $16 \%$ in the period 2001-2003, but numbers were on the increase again in the period 2003 to 2005. Still, in 2005 , the number of jobs is $11 \%$ lower as compared to 2001. In terms of sales, the branch realizes strong growth, especially between 2004 and 2006. In the period 2000-2004 sales growth was $+6 \%$, whereas the 2004-2006 period showed an increase of 22 percentage points.

A list of all firms with five or more fulltime employees in this sector was obtained from the Dutch Chamber of Commerce $(\mathrm{CoC})$. After purging the list for empty holdings, firms with several subsidiaries with the same address, and duplicates, 2553 firms remained. A questionnaire was sent to all of these firms by mail in January 2006. Unfortunately, due to the limitations of the database of the $\mathrm{CoC}$, no reliable names of contact person were available. Therefore, the questionnaires were sent to the managing director of all firms.

Ultimately, 203 firms returned a useable questionnaire (a response rate of 8\%). Even though this seems like a low response rate, comparable response rates were obtained in similar micro level studies (e.g. Oerlemans and Meeus 2005; Rooks et al. 2005). Additionally, from several meta-analyses of response rates (e.g. Baruch 1999; Klassen and Jacobs 2001) it may be concluded that, besides the general downward trend in response rates caused by "saturation" of respondents and lack of time, several other explanations can be given for the relatively low response rates. Most importantly, Baruch (1999) finds that surveys mailed to individuals (and about individual characteristics) have a much higher response rate than surveys mailed to organizational representatives. Klassen and Jacobs (2001) find that SMEs, of which the sector sampled in 
Table 2 Non-response analysis

\begin{tabular}{lllll}
\hline & Respondents & Non-respondents & Difference & Significance \\
\hline Size of the firm (in employees) & 23.5 & 27.6 & 4.1 & $0.19^{\mathrm{a}}$ \\
Presence of IORs & $56 \%$ & $51 \%$ & $-5^{\mathrm{d}}$ & $0.29^{\mathrm{b}}$ \\
Presence of innovative activities & $84 \%$ & $79 \%$ & $-5^{\mathrm{d}}$ & $0.36^{\mathrm{b}}$ \\
Spatial distribution (by province) & Total sample & Response & Difference $^{\mathrm{d}}$ & Significance $^{\text {Digne }}$ \\
Drenthe & $1.0 \%$ & $1.4 \%$ & -0.4 & $0.18^{\mathrm{c}}$ \\
Flevoland & $2.5 \%$ & $2.7 \%$ & -0.2 & \\
Friesland & $2.0 \%$ & $1.6 \%$ & 0.4 & \\
Gelderland & $13.4 \%$ & $11.6 \%$ & 1.8 & \\
Groningen & $1.5 \%$ & $2.3 \%$ & -0.8 & \\
Limburg & $5.5 \%$ & $3.5 \%$ & 2.0 & \\
Noord-Brabant & $20.9 \%$ & $14.1 \%$ & 6.8 & \\
Noord-Holland & $14.4 \%$ & $20.6 \%$ & -6.2 & \\
Overijssel & $5.0 \%$ & $4.6 \%$ & 0.4 & \\
Utrecht & $10.9 \%$ & $13.0 \%$ & -2.1 & \\
Zeeland & $0.5 \%$ & $0.6 \%$ & -0.1 & \\
Zuid-Holland & $22.4 \%$ & $24.1 \%$ & -1.7 & \\
\hline
\end{tabular}

a $\mathrm{T}$ test

b Phi-test

${ }^{\mathrm{c}}$ Chi-square test

${ }^{\mathrm{d}}$ Difference in percentage points

this research is predominantly composed, generally respond less to surveys as compared to their larger counterparts. When taking all of these aspects into account the response rate of $8 \%$ is not unexceptional.

Nevertheless, the fact that a large group of firms did not respond raises the question whether the data might suffer from a sample bias. Therefore, a non-response analysis has been performed. A randomly selected group of 179 non-respondents were approached by telephone and asked to give answers to several key questions in the questionnaire. These key questions included the size of the firm, the presence of interorganizational relations, and whether the firms performed any innovative activities. These questions were asked since they include an indication of firm performance (the dependent variable) as well as information with regard to the main independent variable. Moreover, firm size was included since it is a variable that is likely to influence response bias. Of these 179 firms, 130 were willing to cooperate (response rate of $73 \%$ ). The data obtained from these non-respondents allows for a comparison of the respondents and the non-respondents and provide valuable information with regard to the representativeness of the data. For several other variables, the respondents could be compared to the whole population of firms in the automation services, since these variables could be extracted from the $\mathrm{CoC}$ database. A comparison between the respondents, non-respondents and the entire population can be found in Table 2 . 
From Table 2 it can be derived that there are no significant differences between the respondents and the non-respondents with regard to the variables under scrutiny. Moreover, there are no significant differences between the respondents and the populations as a whole. Therefore, it can be concluded that there do not seem to be any structural differences between the respondents and the non-respondents and that there is no indication of sample bias in the data.

\section{Data analysis and results}

First, in order to assess whether agglomeration economies and the localization of interorganizational linkages always coincide, the different indicators of agglomeration economies are used as predictors of the different types of localized inter-organizational linkages. In these analyses, the firm level variables described earlier are used as control variables as well. An OLS-regression has been estimated to explain the share of localized external linkages. A Binary logistic regression has been estimated to explain whether or not a firm has a localized main IOR. The results of this analysis are presented in Table 3.

From Table 3, it becomes clear that agglomeration effects are far from perfect predictors of the localized inter-organizational linkage of firms. The level of localization of a region is of importance as is the level of localization and urbanization of the neighboring regions, but this only holds for the share of localized external linkages. For the presence of a localized main IOR, none of the agglomeration effects are of importance. Only having more IORs (positively) and being larger (negatively) are associated with this measure of localized inter-organizational linkage.

For both indicators of localized inter-organizational linkages it is found that the share of explained variance by agglomeration economies is low. As a result, it can be concluded that being located in a spatial concentration of firms is not a guarantee that firms will also maintain localized inter-organizational linkages. This finding is in line with earlier firm-level research (e.g. Sohn 2004). It does, however, point at the importance of disentangling their effects at the level of the firm. If agglomeration economies and localized inter-organizational linkages do not necessarily coincide, then what is their relative influence on the innovativeness of firms? In order to provide an answer to this question, binary logistic regressions will be estimated to predict whether firms produced innovative products in three categories of newness. In each of these models the indicators of agglomeration effects, localized inter-organizational linkage, and the firm level control variables will be used as explanatory variables. ${ }^{4}$

\footnotetext{
4 Despite the fact that both firm-level and regional characteristics are used in a single model, multilevelanalysis has not been adopted since this study does not focus on explaining differences within versus between regions. To ensure that this choice does not lead to a violation of the homoscedasticity assumption, as is possible when linking regional level data to individual firms (Snijders and Bosker 1999), it has been tested whether there is a difference between the -2 Log Likelihood of an OLS-regression and that of a random intercept-only model for all dependent variables. The difference between the two was not significant, which implies that the differences between regions are non-significant and a multilevel analysis is not necessary (procedure adopted from: Boschma and Weterings 2005).
} 
Table 3 Agglomeration effects and localized inter-organizational linkages

\begin{tabular}{lcc}
\hline & Localized external linkages (\%) & Local IOR $^{\mathrm{a}}$ \\
\hline Constant & 56.21 & 1.28 \\
Agglomeration effects & & \\
Localization effects & $\mathbf{0 . 3 2} * *$ & 1.87 \\
Spatial lag of localization effects & $\mathbf{- 0 . 3 3 * *}$ & -6.00 \\
Urbanization effects & -0.170 & -0.01 \\
Spatial lag of urbanization effects & $\mathbf{0 . 3 8 *}$ & 0.01 \\
R\&D intensity of region & 0.13 & -0.01 \\
Spatial lag of R\&D intensity of region & 0.09 & 0.01 \\
Regional level of education & & -0.01 \\
Firm level control variables & & $-\mathbf{0 . 6 3} * * *$ \\
Size (ln) & -0.07 & -0.02 \\
Age & 0.08 & -0.30 \\
Part of larger organization & -0.01 & 0.01 \\
R\&D intensity of firm & 0.07 & -0.01 \\
Share of highly educated personnel & -0.08 & $\mathbf{0 . 8 9} * * *$ \\
Number of IORs & 0.03 & \\
Model indicators & & $34.7^{\mathrm{b}}$ \\
Adjusted $R$-square (\%) & 1.8 & 0.000 \\
Significance & 0.229 & 203 \\
$N$ & 203 & \\
\hline
\end{tabular}

* Significant at the $10 \%$ level

** Significant at the $5 \%$ level

*** Significant at the $1 \%$ level

${ }^{\text {a }}$ Binary logistic regression

b Nagelkerke's Pseudo R-square

Before doing so, however, bivariate correlations and variance inflation factors (VIFs) have been calculated for all independent variables in order to check for multicollinearity problems (see Table 4). As can be derived from Table 4, a relatively high bivariate correlation exists between the indicators for economies of urbanization and localization. However, the VIFs of both variables are still moderately low (i.e. well below the threshold level of 10), and including both variables in a model simultaneously will therefore not lead to multicollinearity problems. This does not hold, however, for the spatial lags of these variables, for which the VIFs do approach the critical value. To ensure that multicollinearity between these spatial lags does not lead to imprecise parameter estimates, all analyses have also been conducted excluding one of the spatial lags each time, in which case the VIF drops to 1.446 respectively 2.016 and multicollinearity is no longer a problem. The results are almost identical. Therefore, only the results including both variables have been included in this paper.

The same problem occurs in the case of the percentage of localized external linkages and its squared term (high bivariate correlation and VIFs). As discussed earlier, the 


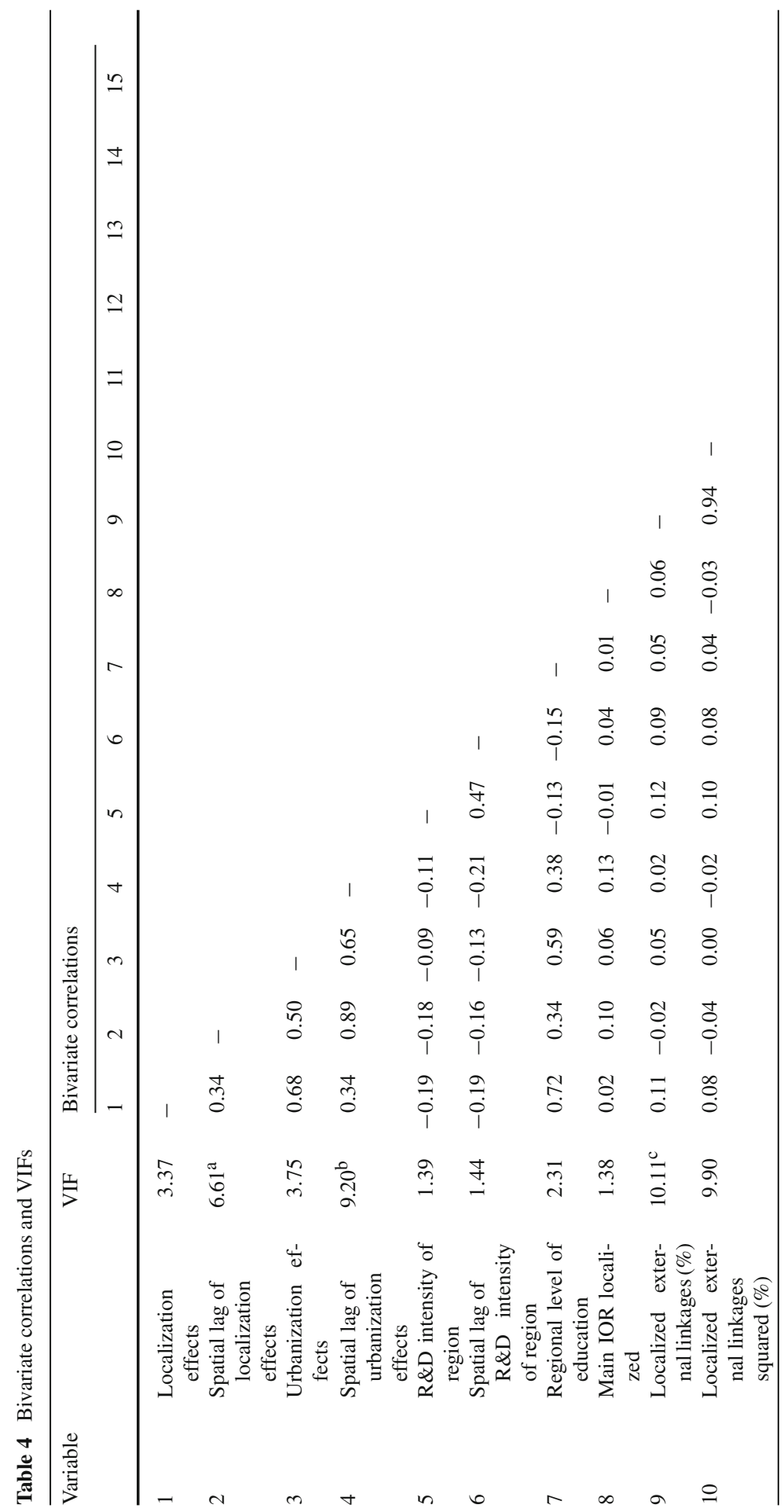




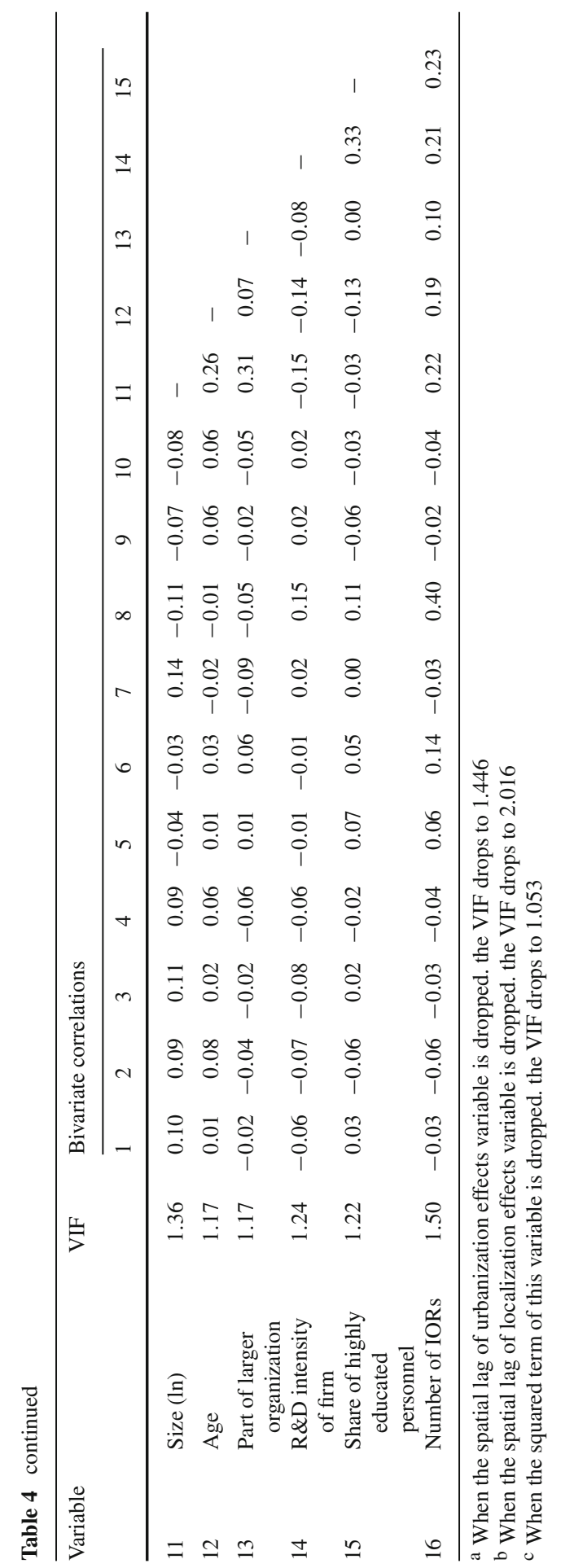


squared term has been included to allow for a non-linear relationship between the percentage of localized external linkages and firm innovativeness and has therefore been kept in the analyses. Again, to ensure that this multicollinearity does not lead to imprecise parameter estimates, all analyses have also been conducted without the squared term, in which case the VIF drops to 1.053 and multicollinearity is no longer a problem. The results are highly similar. Therefore, only the results including both variables have been included in this paper.

The results of the binary logistic regressions are reported in Table 5. Three different models have been estimated, namely one for firm innovativeness at the three distinguished levels of newness of products. Model 1 reports the results regarding the production of improved versions of products that were already generated by the firm. Model 2 uses the production of products that are new to the firm as the dependent variable, whereas model 3 uses the production of products that are new to the markets as a whole as the dependent variable. On the scale of newness of innovations model 1 represents incremental forms of innovation, model 2 represents innovations of intermediate levels of newness, and model 3 represents radical innovations. In binary logistic models the probability of occurrence of an event is estimated, which in this particular case is the likelihood that a firm will have introduced an innovative product in the category of newness under scrutiny. The models are estimated with a maximum likelihood procedure.

Several interesting results can be derived from these analyses. The production of improved versions of products already produced by the firm (i.e. model 1) is positively influenced by the total number of IORs that a firm has. The fact that the localization of inter-organizational linkages does not play a role at all indicates that the resources that are required to improve existing products can easily be exchanged between firms over large geographical distances. Agglomeration effects influence the likelihood that firms will generate improved products as well. However, whereas localization effects have a positive effect on this incremental form of innovativeness, urbanization effects have a negative effect. A possible explanation is that being close to many similar firms (i.e. localization economies) allows for quick identification of the products and services of other firms, which in turn generates ideas for changes to and applications of products you are already producing. With regard to the negative effect of urbanization economies it can be concluded that the downsides of being in a highly urbanized area (congestion, land prices, and so on) dominate the benefits of these locations. Finally, the effects of agglomeration economies for this type of innovation are regionally bounded as none of the spatial lags of the regional variables has a significant influence.

Regarding the generation of products that are new to the firm (model 2), high levels of urbanization economies are detrimental. This indicates that for the generation of these innovations simply being in an urban region is not sufficient, and can even be harmful instead. However, actively interacting with and obtaining knowledge from other local organizations does influence the generation of products that are new to the firm. The relationship between these variables follows an inverted U-shape. For clarity, the isolated effect of the percentage of localized inter-organizational linkages on the propensity of a firm to generate products that are new to that firm is plotted in Fig. 1. Figure 1 indicates that moderate levels of localized external linkage (up to about $35 \%$ ) are conducive to this type of innovative performance, whereas very high 
Table 5 Spillovers. economic linkages. and innovativeness

\begin{tabular}{|c|c|c|c|}
\hline & $\begin{array}{l}\text { Improved } \\
\text { products }\end{array}$ & $\begin{array}{l}\text { Products new } \\
\text { to the firm }\end{array}$ & $\begin{array}{l}\text { Products new } \\
\text { to the market }\end{array}$ \\
\hline & Model 1 & Model 2 & Model 3 \\
\hline Constant & $-6.26 * * *$ & 4.38 & 4.33 \\
\hline \multicolumn{4}{|l|}{ Agglomeration effects } \\
\hline Localization effects & $1.01 *$ & 0.87 & $1.10 * *$ \\
\hline Spatial lag of localization effects & 0.17 & -1.74 & $-2.50 * *$ \\
\hline Urbanization effects & $-0.15 * * *$ & $-0.14 * * *$ & $-0.18 * *$ \\
\hline Spatial lag of urbanization effects & 0.01 & 0.01 & 0.03 *** \\
\hline R\&D intensity of region & -0.01 & -0.02 & 0.00 \\
\hline Spatial lag of $R \& D$ intensity of region & -0.01 & -0.02 & 0.00 \\
\hline Regional level of education & 0.01 & 0.03 & -0.03 \\
\hline \multicolumn{4}{|l|}{ Localized inter-organizational linkages } \\
\hline Main IOR localized & 0.03 & -0.03 & $0.48^{*}$ \\
\hline Localized external linkages (\%) & 0.02 & $0.04 * *$ & 0.01 \\
\hline Localized external linkages (squared) (\%) & 0.00 & $-\mathbf{0 . 0 1} * * *$ & 0.00 \\
\hline \multicolumn{4}{|l|}{ Other firm Characteristics } \\
\hline Size $(\ln )$ & 0.27 & $0.45 * *$ & $0.51 * * *$ \\
\hline Age & 0.00 & -0.03 & -0.03 \\
\hline Part of larger organization & -0.31 & $-0.74 *$ & -0.01 \\
\hline$R \& D$ intensity of firm & 0.00 & $0.05^{* * *}$ & $0.08 * * *$ \\
\hline Share of highly educated personnel & 0.00 & 0.01 & 0.01 \\
\hline Number of IORs & $0.38 * *$ & 0.18 & 0.11 \\
\hline \multicolumn{4}{|l|}{ Model indicators } \\
\hline Pseudo $R$-square (\%) & 25.1 & 36.5 & 45.3 \\
\hline Significance & 0.01 & 0.000 & 0.000 \\
\hline$N$ & 203 & 203 & 203 \\
\hline
\end{tabular}

$* 10 \%$ significance level

** $5 \%$ significance level

$* * * 1 \%$ significance level

levels of localized linkage are detrimental instead. This finding provides evidence that combinations of local and non-local ties are most conducive to the innovative performance of firms (similar to Fritsch 2004; Sternberg and Arndt 2001). Moreover, the fact that high levels of localized external linkage are detrimental to this type of innovative performance indicates that a high local focus can blind a firm to innovative opportunities that might be present outside of its region (Boschma 2005). In short, for this type of innovative performance contacts between a firm and other organizations is necessary, simply being in an urbanized region is not only insufficient but even harmful.

Regarding the effect of firm-level variables on the generation of products that are new to the firm it can be concluded that larger firms and firms with higher levels of 


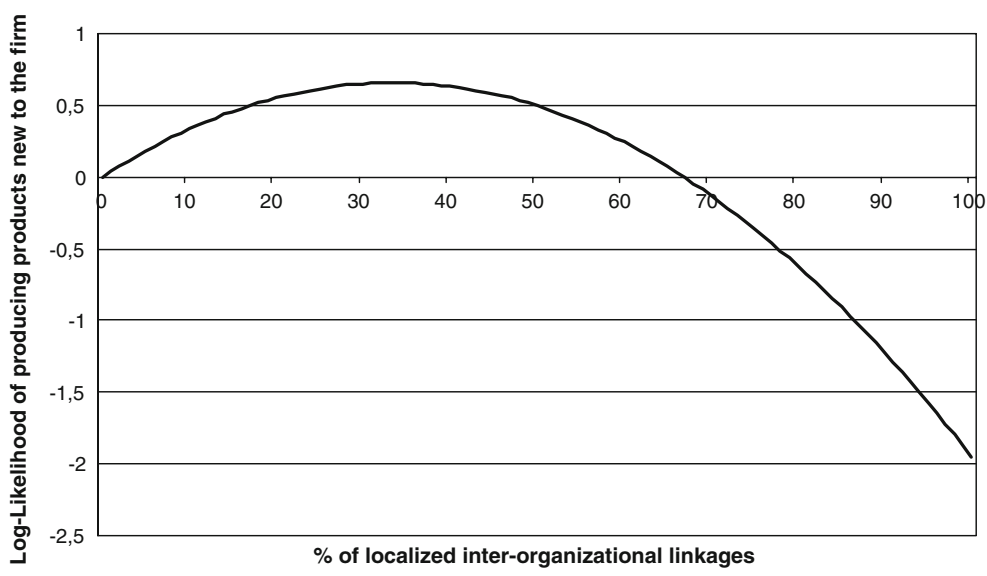

Fig. 1 Localized external linkages and the generation of products new to the firm

R\&D intensity are more likely to generate such products, whereas firms that are part of a larger organizational entity are less likely to produce this type of innovations. Whereas the first two findings are not very surprising, the latter finding is somewhat unexpected. A possible explanation might be that units of larger organizational entities have less strategic freedom to develop and introduce new products as this function is dedicated to a specialized R\&D facility.

The generation of products that are new to the markets as a whole (model 3) is rather strongly influenced by agglomeration effects. The findings regarding localization effects and urbanization effects are each other's mirror image. Whereas it is conducive to this type of innovation to be localized in a region with high levels of localization but detrimental to be located in a region with neighbors with high levels of localization, the opposite holds for the level of urbanization. This seems to reflect that the benefits of spatial concentrations of firms in general are not bounded by the region, whereas the disadvantages of such spatial concentrations are. As a result, it is beneficial to be located near a spatial concentration of firms but not to be located in it. Regarding spatial concentrations of firms from the same sector, the opposite holds. Being in such a concentration yields positive results, whereas being located near such a region is detrimental for a firm's radical innovative performance.

Regarding a firm's level of inter-organizational linkage it is found that having a localized main IOR has a weak positive influence on the generation of products that are new to the market, whereas having IORs in general does not. This indicates that the exchange of resources conducive to more radical forms of innovation is strongly influenced by geographical proximity. The fact that localization of a firm's main IOR has an influence on the generation of products new to the market, but the level of localization of external linkages in general does not, indicates that the development of such innovations requires relatively intense forms of active collaboration between organizations. Furthermore, firm size and high levels of R\&D intensity are positively associated with the generation of products that are new to the market as well. 


\section{Discussion}

The research presented in this paper set out to add firm-level insights with regard to the role of geographical proximity for the innovativeness of firms by disentangling two forms of geographical proximity and by taking into account several types of innovative performance. In line with earlier research, it is found that agglomerations and localized inter-organizational linkages do not always coincide. This finding puts further emphasis on disentangling the effects of both types of geographical proximity on firm innovativeness.

By disentangling the effects of both forms of geographical proximity, it is shown that both have different effects on different types of innovative performance. Urbanization economies have a negative effect on the innovative performance of firms, whereas localization economies generally have a positive effect. These findings indicate that being located in an agglomeration of firms is not necessarily beneficial for the innovative performance of a firm, but that the effects depend on the composition of firms in the agglomeration. Agglomerations of firms that operate in the same sector are likely to increase the innovativeness of firms, possibly due to intensified local imitation. In addition to these effects, in the case of products that are new to the market, the effects of the spatial lags of the agglomeration variables work in the opposite direction. This implies that being close to a concentration of firms has the opposite effect on firm innovativeness as being inside the concentration of firms. Combining both findings leads to the conclusion that the location that is most conducive to a firm's innovative performance is in a region with a high concentration of firms from the same sector neighboring a region with a high concentration of firms in general.

Regarding localized inter-organizational linkages, indications are found that especially combinations of local and non-local inter-organizational linkages are conducive to innovation. However, the findings also show that this conclusion only holds for a specific type of innovation, namely the generation of products new to the firm, indicating that it is fruitful to distinguish between different types of innovative performance when analyzing the effects of geographical proximity on the innovative performance of firms. This conclusions is further substantiated by the fact that, whereas IORs in general (i.e. localized or not) are conducive to the generation of improved versions of existing products, only localized IORs are conducive to the generation of products that are new to the market.

On the whole it can be concluded that the fact that geographical concentration and localized external linkages are weakly linked at the firm level emphasizes the importance of disentangling the two mechanisms through which geographical proximity influences innovative firm performance. Furthermore, the fact that both spatial mechanisms produce very different effect for different types of innovativeness implies that the findings of studies that do not disentangle both spatial mechanisms might incorrectly attribute effects to either of these forms of geographical proximity.

The findings also provide interesting insights for (local) policy-makers that try to stimulate the innovativeness of firms in their region. The findings show that simply bringing firms together, for example by building science parks, is unlikely to effectively stimulate the innovativeness of firms and might even hamper it. Moreover, stimulating local inter-organizational interacting might be a successful way to stimulate 
the innovativeness of firms, but only up to a certain point. Too high levels of local interaction leads to regional-inertia and might hamper the innovativeness of firms. Furthermore, the findings indicate that different types of innovation are affected by different variables. Policy aimed at increasing radical innovativeness is likely to be more successful if it aims at bringing about long-term intensive collaborations between geographically proximity organizations, whereas incremental types of innovativeness are already influenced by bringing firms that conduct similar economic activities together. Finally, the findings also point at the importance of in-house R\&D, especially for more radical types of firm innovativeness. In this regard, simply stimulating private R\&D might be an easy way to increase firm innovativeness.

Even though the study presented in the above provides additions to the relatively scare firm-level literature on the effects of geographical proximity on firm innovativeness, it suffers from several drawbacks as well. First, the actual utilization of agglomeration effects as well as the actual transmission of resources through localized inter-organizational linkages is not observed. In order to provide a more detailed analysis of why and how spatial characteristics and inter-organizational linkages influence certain types of innovativeness, these flows have to be directly measured.

Second, the focus on a single sector limits the generalizability of the results. The relatively modest effects of regional differences on firm innovativeness might be peculiar to the automation services industry as firms in this industry are often intensive ICTusers. The products that they work on are often easily made digital and can therefore easily be exchanged over long distances, which reduced the importance of geographical proximity (Knoben and Oerlemans 2008). Analyzing data from sectors that do not have such characteristics (i.e. most manufacturing sectors for instance) is likely to yield different results. In order to obtain higher levels of generalizability, therefore, multi-sectoral data will have to be utilized.

Finally, as is often the case in micro-level models, the explanatory power of the models is relatively modest. Even though increasing the explanatory power is hard due to high levels of firm-level heterogeneity (Beugelsdijk 2007), doing so would be highly valuable. Noticeably, it would greatly reduce the risk of omitted variable bias, which occurs when a variable that is not included in the model is both a determinants of the dependent variable and correlates with one or more of the independent variables that is included in the model. If this is the case, model coefficients will be biased and the model will be wrongfully specified. Future research should therefore be extended to include a broader scope of firm level characteristics (also see, Mariani 2004).

Acknowledgments Any views expressed are my own and do not necessarily reflect those of the institutions I am affiliated with. I would like to thank Roderik Ponds and two anonymous reviewers for their valuable comments on earlier versions of this paper.

Open Access This article is distributed under the terms of the Creative Commons Attribution Noncommercial License which permits any noncommercial use, distribution, and reproduction in any medium, provided the original author(s) and source are credited.

\section{References}

Acs ZJ, Audretsch DB (1988) Innovation in large and small firms: an empirical analysis. Am Economic Rev 78(4):678-690 
Ahuja G (2000) Collaboration networks, structural holes, and innovation: a longitudinal study. Adm Sci Q 45(3):425-457

Alberti FG (2006) The decline of the industrial district of Como: recession, relocation or reconversion. Entrep Reg Dev 18(6):473-501

Alcacer J (2006) Location choices across the value chain: how activity and capability influence collocation. Manag Sci 52(10):1457-1471

Appold SJ (1995) Agglomeration, interorganizational networks, and competitive performance in the US metalworking sector. Econ Geogr 71(1):27-54

Arndt O, Sternberg R (2000) Do manufacturing firms profit from intraregional innovation linkages? An empirical based answer. Eur Plan Stud 8(4):465-485

Arundel A, Kabla I (1998) What percentage of innovations are patented? empirical estimates for European firms. Res Pol 27(2):127-141

Audretsch DB, Acs ZJ (1991) Innovation and size at the firm Level. South Econ J 57(3):739-744

Baptista R, Swann P (1998) Do firms in clusters innovate more? Res Policy 27(5):525-540

Baranes E, Tropeano J (2003) Why are technological spillovers spatially bounded? A market orientated approach. Reg Sci Urban Econ 33(1):445-466

Baruch Y (1999) Response rate in academic studies: a comparative analysis. Hum Relat 52(4):421-438

Beugelsdijk S (2007) The regional environment and a firm's innovative performance: a plea for a multilevel interactionist approach. Econ Geogr 83(2):181-199

Boasson V, Boasson E, Macpherson A, Shin H-H (2005) Firm value and geographic competitive advantage: evidence from the US pharmaceutical industry. J Bus 78(6):2465-2495

Boschma RA (2005) Proximity and innovation: a critical assessment. Reg Stud 39(1):61-74

Boschma RA, Weterings ABR (2005) The effect of regional differences on the performance of software firms in the Netherlands. J Econ Geogr 5(5):567-588

Breschi S, Lissoni F (2001) Localised knowledge spillovers vs. innovative milieux: knowledge tacitness reconsidered. Pap Reg Sci 80(1):255-273

Dicken P, Malmberg A (2001) Firms in territories: a relational perspective. Econ Geogr 77(4):345-363

Feldman MP (1999) The new economics of innovation spillovers and agglomeration: a review of empirical studies. Econ Innov New Technol 8(1):5-26

Flyer F, Shaver JM (2003) Location choices under agglomeration externalities and strategic interaction. In: Baum JAC, Sorenson O (eds) Advances in strategic management: geography and strategy, vol 20. Elsevier JAI, Amsterdam, pp 193-214

Fritsch M (2004) Cooperation and the efficiency of regional R\&D activities. Camb J Econ 28(6):829-846

Fritsch M, Franke G (2004) Innovation, regional knowledge spillovers and R\&D cooperation. Res Policy 33(2):245-255

Gatignon H, Tushman ML, Smith W, Anderson P (2002) A structural approach to assessing innovation: construct development of innovation locus, type, and characteristics. Manag Sci 48(9):1103-1122

Gordon IR, Mccann P (2000) Industrial clusters: complexes, agglomerations or social networks? Urban Stud 37(3):513-532

Gustavsen B, Nyhan B, Ennals R (2007) Learning together for local innovation: promoting learning regions. Luxemburg, CEDEFOP

Hagedoorn J, Cloodt M (2003) Measuring innovative performance: is there an advantage in using multiple indicators? Res Policy 32(8):1365-1379

Hagedoorn J, Schakenraad J (1994) The effect of strategic technology alliances on company performance. Strateg Manage J 15(4):291-309

Hansen JA (1992) Innovation, firm size, and firm age. Small Bus Econ 4(1):37-44

Harrison B, Kelley MR, Gant J (1996) Innovative firm behavior and local milieu: exploring the intersection of agglomeration, firm effects, and technological change. Econo Geogr 72(3):233-258

Hendry C, Brown J (2006) Dynamics of clustering and performance in the UK opto-electronics industry. Reg Stud 40(7):707-725

Howells JRL (2002) Tacit knowledge, innovation and economic geography. Urban Stud 39(5-6):871-884

Jaffe AB, Trajtenberg M, Henderson R (1993) Geographic localization of knowledge spillovers as evidenced by patent citations. Q J Econ 108(3):577-598

Klassen RD, Jacobs J (2001) Experimental comparison of Web, electronic and mail survey technologies in operations management. J Oper Manag 19(6):713-728

Kleinknecht A (1991) More evidence on the undercounting of small firm R\&D. Res Policy 20(60):579-587

Kleinknecht A (1996) Determinants of innovation: the message from new indicators. MacMillan, London 
Knoben J, Oerlemans LAG (2006) Proximity and inter-organizational collaboration: a literature review. Int J Manage Rev 8(2):71-89

Knoben J, Oerlemans LAG (2008) The effects of firm relocation on firm performance. Econ Geogr 84(2): $157-183$

Kogut B, Zander U (1992) Knowledge of the firm, combination capabilities and the replication of technology. Organ Sci 3(3):383-397

Lever W (1972) Industrial movement, spatial association and functional linkages. Reg Stud 6(4):371-384

Love JH, Roper S (2001) Location and network effects on innovation success: evidence for UK, German and Irish manufacturing plants. Res Policy 30(4):643-661

Malmberg A, Malmberg B, Lundequist P (2000) Agglomeration and firm performance: economies of scale, localisation, and urbanisation among Swedish export firms. Environ Plan A 32(2):305-321

Mariani M (2004) What determines technological hits? Geography versus firm competencies. Res Policy 33(10):1565-1582

Mitchell W, Singh K (1996) Survival of businesses using collaborative relationships to commercialize complex goods. Strateg Manag J 17(3):169-195

Mota JQ, De Castro LM (2004) Industrial agglomerations as localised networks: the case of the Portuguese injection mould industry. Environ Plan A 36(2):263-278

Moulaert F, Sekia F (2003) Territorial innovation models: a critical review. Reg Stud 37(3):289-302

Narula R (2002) Innovation systems and "inertia" in R\&D location: Norwegian firms and the role of systemic lock-in. Res Policy 31:795-816

Oerlemans LAG, Meeus MTH (2005) Do organisational and spatial proximity impact on firm performance? Reg Stud 39(1):89-104

Oerlemans LAG, Meeus MTH, Boekema FWM (1998) Do networks matter for innovation? The usefulness of the economic network approach in analysing innovation. Tijdschr Econ Soc Geogr 89(3):298-309

Oerlemans LAG, Meeus MTH, Boekema FWM (2001) Firm clustering and innovation: determinants and effects. Pap Reg Sci 80(1):337-356

Phelps NA (1992) External economies, agglomeration and flexible accumulation. Trans Inst Bri Geogr 17(1):35-46

Pittaway L, Robertson M, Munir K, Denyer D, Neely A (2004) Networking and innovation: a systematic review of the evidence. Int J Manag Rev 5-6(3-4):137-168

Rooks G, Oerlemans L, Buys A, Pretorius T (2005) Industrial innovation in South Africa: a comparative study. S Afr J Sci 101(3-4):149-150

Rosenkopf L, Almeida P (2003) Overcoming local search through alliances and mobility. Manag Sci 49(6):751-766

Snijders TAB, Bosker RJ (1999) Multilevel analysis: an introduction to basic and advanced multilevel modeling. Sage, London

Sohn J (2004) Do birds of a feather flock together? Economic linkage and geographic proximity. Ann Reg Sci 38(1):47-73

Sternberg R, Arndt O (2001) The firm or the region: what determines the innovation behavior of European firms. Econ Geogr 77(4):364-382

Stuart TE (2000) Interorganizational alliances and the performance of firms: a study of growth and innovation rates in a high-technology industry. Strateg Manag J 21(8):791-811

Torre A, Rallet A (2005) Proximity and localization. Reg Stud 39(1):47-59

Tsai WP (2001) Knowledge transfer in intraorganizational networks: effects of network position and absorptive capacity on business unit innovatio and performance. Acad Manag J 44(5):996-1004

Van Oort F (2002) Agglomeration, economic growth and innovation: spatial analysis of growth- and R\&D externalities in the Netherlands. Tinbergen Institute, Rotterdam

Van Stel AJ, Nieuwenhuijsen HR (2004) Knowledge spillovers and economic growth: an analysis using data of Dutch regions in the period 1987-1995. Reg Stud 38(4):393-407

Wheeler CH (2006) Productivity and the geographic concentration of industry: the role of plant scale. Reg Sci Urban Econ 36(3):313-330 